\title{
Symptomatic rickets in adolescence
}

\author{
H Narchi, M El Jamil, N Kulaylat
}

\begin{abstract}
Aim-To describe 21 cases of symptomatic rickets in adolescents.

Methods-The setting was a primary and secondary care hospital in Saudi Arabia providing medical care to Saudi Arab company employees and their families. Cases of symptomatic rickets diagnosed between January 1996 and December 1997 in adolescents aged 10 to 15 years were assessed with respect to clinical presentation, biochemical and radiological evaluation, dietary assessment, and estimation of sun exposure.

Results-Symptomatic rickets developed in 21 adolescents ( 20 females), with a prevalence rate of 68 per 100000 children years. Presentation included carpopedal spasms $(n=12)$, diffuse limb pains $(n=6)$, lower limbs deformities $(n=2)$, and generalised weakness $(n=1)$. Biochemical findings included hypocalcaemia $(\mathbf{n}=19), \quad$ hypophosphoraemia $(\mathbf{n}=9)$, raised serum alkaline phosphatase $(n=21)$ and parathormone $(n=7)$, and reduced 25-hydroxyvitamin D concentrations $(\mathbf{n}=7)$. Radiological studies were suggestive of rickets in only eight children. All children had an inadequate dietary calcium and vitamin $D$ intake. All but one had less than 60 minutes sun exposure per day. Conclusion-Even in sunny climates, adolescents, especially females, can be at risk of rickets. Hypocalcaemic tetany and limb pains were the most common presenting symptoms. Radiological evidence was not present in every case.

(Arch Dis Child 2001;84:501-503)
\end{abstract}

Keywords: rickets; hypocalcaemia; nutrition; sun

In developing countries nutritional rickets is common in infancy and the practice of routine vitamin $\mathrm{D}$ supplementation in this age group is well established. In those countries, although infants and adult women are at increased risk, no affected adolescents have been reported. The development of nutritional rickets during rapid growth in puberty has been reported in adolescent Asians and North Africans living in developed countries with a colder climate. This was attributed to low vitamin D intake, lack of sunlight, skin pigmentation, and a possible genetic disability to synthesise cholecalciferol or to convert it to its more active metabolites, combined with increased metabolic demands as a result of rapid growth at puberty. ${ }^{1}$

We report the unexpected development of symptoms of rickets in a series of Saudi Arab adolescents living in a sunny environment. The clinical presentation, and biochemical and radiological findings are discussed, as well as the risk factors for the development of rickets.
Materials and methods

Our institution provides free primary and secondary medical care to a population of Saudi Arab company employees and their families, all of whom are registered in our institution where they receive curative and preventive care, including mandatory immunisations. We report all cases of symptomatic rickets diagnosed in adolescents (aged 10 to 15 years) in our institution between January 1996 and December $1997(n=21)$; this constituted the nominator for prevalence calculation, with the denominator being the total number of adolescents in the same age group who were registered and eligible for care in our institution during that same two year period $(n=30880)$.

Symptomatic rickets was defined as symptoms or signs attributable to rickets (tetany, convulsions, bone deformities or pain, muscle weakness). Rickets was diagnosed on the basis of abnormal biochemical results (raised serum alkaline phosphatase, with or without raised parathormone concentration, low serum 25hydroxyvitamin D concentration, or raised serum 1,25-hydroxyvitamin D concentration), supported in some cases by radiological signs, together with evidence of clinical and biochemical normalisation after vitamin $\mathrm{D}$ and calcium supplemental therapy. Children with renal or hepatic disease, malabsorption, or on anticonvulsant therapy were excluded.

The clinical, anthropometric, biochemical, and radiological data were collected. Standard deviation scores ( $\mathrm{z}$ scores) for height and weight were calculated according to the World Health Organisation 1985 standard. The average daily dietary intake of calories, calcium, and vitamin $\mathrm{D}$ was estimated using the seven day recall method in an interview with a dietician. Estimation of the average daily duration of sun exposure (uncovered face and hands at least) was based on information given during an interview with a social worker. The average daily duration of sun exposure during school term, weekend, and holidays, and also four trimesters with wide temperature variations (as sun exposure is reduced in the hottest seasons) was determined. The mean daily exposure was a weighted average of the values obtained for a one year period. All affected children received standard therapy, dietary advice, and follow up visits.

\section{Results}

A total of 21 patients were identified with rickets: 20 females and one male. The median age was 13 years (range 11 to 15 years). All came from families with equivalent socioeconomic background (based on the employment grade code of the father). All were between Tanner pubertal stage 2 and 4, and all had a height 
Table 1 Demographic and clinical findings at presentation

\begin{tabular}{|c|c|c|c|c|c|}
\hline \multirow[b]{2}{*}{ Parameter } & \multicolumn{5}{|l|}{ Mode of presentation } \\
\hline & $\begin{array}{l}\text { All } \\
n=21\end{array}$ & $\begin{array}{l}\text { Tetany } \\
n=12\end{array}$ & $\begin{array}{l}\text { Pains } \\
n=6\end{array}$ & $\begin{array}{l}\text { Weakness } \\
n=1\end{array}$ & $\begin{array}{l}\text { Deformities } \\
n=2\end{array}$ \\
\hline Age (y) & $13(11-15)$ & $12.5(11-15)$ & $13.5(12-14)$ & $12(12)$ & $13.5(13-14)$ \\
\hline Duration of symptoms (days) & $7(1-720)$ & $2(1-120)$ & $195(2-700)$ & $7(7)$ & $710(700-720)$ \\
\hline z score for weight & $-9.3(-2.63$ to 0.78$)$ & $-0.93(-2.54$ to 0.78$)$ & $-0.64(-2.13$ to 0.23$)$ & -2.63 & $-1.1(-1.84$ to -0.53$)$ \\
\hline $\mathrm{z}$ score for height & $-1.4(-3.47$ to 0.58$)$ & $-1.63(-2.57$ to 0.58$)$ & $-1.1(-2.6$ to -0.66$)$ & NA & $-2.4(-3.47$ to -1.4$)$ \\
\hline Daily dietary calcium intake $(\mathrm{mg})$ & $490(43-1040)$ & $502(43-870)$ & $380(574-1040)$ & NA & $395(395)$ \\
\hline Daily dietary vitamin D intake $(\mu \mathrm{g})$ & $2.8(1-15.5)$ & $2.8(1-15.5)$ & $1.8(1-7.3)$ & NA & $13.5(13.5)$ \\
\hline Amount of daily soft drinks (ml) & $750(375-1500)$ & $750(375-1500)$ & $375(375-750)$ & NA & $375(375)$ \\
\hline Daily exposure to sun (min) & $15(10-60)$ & $20(10-60)$ & $15(15-20)$ & NA & $15(15)$ \\
\hline
\end{tabular}

Results expressed as median (range).

velocity between 6 and $11 \mathrm{~cm}$ per year. Half the diagnoses were made in the summer, one third in spring, and the rest in autumn.

Table 1 summarises the clinical presentation. Twelve children presented with hypocalcaemic tetany (carpopedal spasms), six with diffuse limb pains, two with lower limb deformities (genu valgum), and one with progressive muscle weakness. There was no significant age difference with the mode of presentation. The median duration of symptoms before presentation to the hospital was four days; this was associated with the mode of presentation: seven days (muscular weakness), 12.3 days (tetany), 267 days (pains), and 710 days (lower limbs deformities).

Table 2 summarises the biochemical data. A total of 19 children were hypocalcaemic, including the 12 with tetany. Nine children had a low serum phosphorus concentration; serum parathormone was measured in seven children and was increased in all of them; serum alkaline phosphatase was increased in all children. The product of serum calcium by phosphorus, normally equal to $3.3 \mathrm{mmol}^{2} / 1^{2}$ in the international system (or $40 \mathrm{mg}^{2} / \mathrm{dl}^{2}$ in the metric system), was reduced in all but one child. ${ }^{2}$ Vitamin D concentrations were measured in seven children; all had reduced serum 25hydroxyvitamin D concentration and increased 1,25-dihydroxyvitamin D concentration.

Radiological studies were suggestive of rickets in eight of 18 children (44\%) who underwent $x$ ray examination: in two thirds with bone pains, one third with tetany, and in all with lower limb deformities. The findings included transverse metaphyseal lucent bands, metaphyseal fraying, and osteopenia.

There were no differences in the $\mathrm{z}$ scores for weight or height in the different modes of clinical presentation (table 1). Dietary evaluation revealed that none were vegetarians. All received a daily dietary calcium intake below the $1200 \mathrm{mg}$ recommended daily allowance for that age group. None was receiving vitamin $\mathrm{D}$

Table 2 Biochemical results at presentation

\begin{tabular}{|c|c|c|c|c|c|c|}
\hline Serum parameter & Normal values & $\begin{array}{l}\text { All } \\
n=21\end{array}$ & $\begin{array}{l}\text { Tetany } \\
n=12\end{array}$ & $\begin{array}{l}\text { Pains } \\
n=6\end{array}$ & $\begin{array}{l}\text { Weakness } \\
n=1\end{array}$ & $\begin{array}{l}\text { Deformities } \\
n=2\end{array}$ \\
\hline Calcium (mmol/l) & $2.2-2.7$ & $1.62(0.3)$ & $1.45(0.1)$ & $1.9(0.2)$ & $1.5(0)$ & $1.8(0.1)$ \\
\hline Phosphorus (mmol/l) & $1.1-1.8$ & $1.2(0.4)$ & $1.4(0.2)$ & $0.9(0.4)$ & $0.9(0)$ & $0.8(0.2)$ \\
\hline $\mathrm{Ca} \times \mathrm{P}$ product $\left(\mathrm{mmol}^{2} / 1^{2}\right)$ & 3.3 & $1.8(0.1)$ & $1.9(0.1)$ & $1.8(0.3)$ & $1.4(0)$ & $1.5(0.4)$ \\
\hline Parathormone (pmol/1) & $1.0-5.2$ & $35(3.6)$ & $35(3.6)$ & NA & NA & NA \\
\hline Alkaline phosphatase (U/l) & $80-280$ & $818(440)$ & $628(380)$ & $986(506)$ & $1250(0)$ & $1199(338)$ \\
\hline 25-hydroxyvitamin D (nmol/1) & $10-80$ & $5.8(3.8)$ & $4.6(2.4)$ & $5.2(0)$ & NA & NA \\
\hline 1,25-hydroxyvitamin D (pmol/1) & $38-150$ & $170(70)$ & $141(33)$ & $286(0)$ & NA & NA \\
\hline
\end{tabular}

Values expressed as mean (SD). supplementation. Three quarters had a daily vitamin $\mathrm{D}$ intake below the recommended daily allowance of $10 \mu \mathrm{g}$. All but two drank daily at least one can of carbonated soft drink $(375 \mathrm{ml})$, and half drank more than two cans daily.

The median daily sun exposure (table 1 ) was estimated at 15 minutes (range 10 to 60 minutes). Exposure for less than 60 minutes was reported in all but one patient, and three of four were exposed for less than 30 minutes.

Tetanic manifestations were rapidly controlled with intravenous calcium infusions. Intramuscular vitamin $\mathrm{D}$ therapy, followed by oral vitamin $\mathrm{D}$ and calcium supplementation, achieved normalisation of the clinical, biochemi$\mathrm{cal}$, and radiological signs of active rickets.

\section{Discussion}

Nutritional rickets may be caused by inadequate vitamin $\mathrm{D}$ and/or calcium intake, especially during phases of rapid growth. Cholecalciferol is produced in the skin under the influence of ultraviolet light, metabolised in the liver to 25-hydroxycholecalciferol, and subsequently hydroxylated in the kidneys to 1,25dihydroxycholecalciferol. This then acts on the intestine, bone, and kidney to provide calcium and phosphorus for bone mineralisation and neuromuscular activity.

During the study period, the calculated crude prevalence rate of symptomatic rickets in our institution in children aged 10 to 15 years $(n=30880)$ was 68 cases per 100000 children years. Although this is not a true population based study and no ascertainment by other sources was used, the actual prevalence of this condition is probably even higher in this population. Only symptomatic cases were studied and no routine screening of the population was undertaken. The prevalence of subclinical rickets is therefore likely to be even greater. Assessment of dietary intake and sun exposure by history alone has limitations of accuracy. 
However it was the best method available for this study because home and school visits to assess dietary intake or sun exposure would have been culturally unacceptable.

More than half of the cases presented with acute hypocalcaemic tetany, a potentially life threatening problem. Limb pain was also common as a presenting symptom. Lower limb deformity suggestive of rickets occurred in only two cases. The duration of symptoms prior to diagnosis varied for a number of reasons. Eight families (out of 12) initially attributed tetany to hysterical reactions in adolescent females. Most families did not immediately seek medical attention regarding vague or non-specific symptoms such as weakness or pain. Although lower limb deformity is a frequent reason for families seeking medical advice, the diagnosis of rickets was delayed in our patients. This can be explained by the fact that adolescent Saudi Arab patients of both sexes dress traditionally with a long garment, so that lower limb deformities may be easily overlooked.

Of interest is that the product of serum calcium and phosphorus was reduced in all but one patient, reflecting the inability of the secondary parathyroid response to normalise calcium in children with rickets. In association with a raised serum alkaline phosphatase concentration, this product constituted a useful diagnostic parameter for rickets, as reported previously. ${ }^{2}$

Unlike the study by Moncrieff et al in which all the reported adolescents had radiologically active rickets, ${ }^{1}$ this occurred in less than half of the children in our series. The reasons for the difference are not clear. The duration of symptoms in that study was not specified, and the higher rate of radiological anomalies they observed might have been caused by a longer duration of illness in their patients.

There is no agreed policy of vitamin D supplementation for adolescents in Saudi Arabia, nor for supplementation in food products. Dietary calcium intake in our patients was well below the recommended daily amount of 1200 $\mathrm{mg}$, and the dietary vitamin $\mathrm{D}$ intake was also below the recommended $10 \mu \mathrm{g}$ daily. Although in some African countries children with insufficient dietary calcium develop rickets, the reduced serum 25-hydroxyvitamin D concentrations in our patients suggest that vitamin D deficiency was the main factor in their cases. All drank carbonated beverages which have a high phosphorus content, and this is a predisposing factor for hypocalcaemia. ${ }^{3} \mathrm{Al}-$ though in that case hyperphosphataemia might be expected, the low serum phosphate concentrations we observed could have been caused by the limited consumption of milk.

Although the occurrence of rickets in a warm and sunny country seems surprising, increased skin pigmentation and limited exposure to sunlight may be important. The dress code for Saudi Arab women is strict and involves veiling of the face and total coverage of the body with long garments, explaining why more females developed rickets. In addition, with hot temperatures throughout most of the year, outdoor recreational activities are restricted to the relatively mild winter. Rickets has been described in young adolescent immigrants coming to developed countries from Asia and North Africa, and has been attributed to increased requirements for vitamin $\mathrm{D}$ at a time of increased growth velocity, lack of sunlight, and increased skin pigmentation. ${ }^{4}$ Regional variation in the prevalence of rickets among Asian communities in Britain was mainly determined by the effects of latitude and the effects of an urban environment on exposure to ultraviolet radiation. ${ }^{5}$ Inadequate exposure to the sun in developing countries has also been reported as a cause for rickets in infants and women. ${ }^{6-10}$

It has been estimated that exposure of the face for one hour to sunlight each day may prevent rickets. ${ }^{11}$ The exposure required to maintain normal serum 25-hydroxyvitamin D concentrations in breast fed infants less than 6 months of age was 30 minutes per week if wearing only a diaper, or two hours per week if fully clothed but without a hat. The antirachitic property of sun exposure has also been found to prevent the development of anticonvulsant induced rickets. ${ }^{12}$

In conclusion, despite living in a sunny climate, female adolescents in our population are at risk of developing rickets as a result of dietary deficiency and inadequate exposure to sunshine. Acute hypocalcaemic manifestations and non-specific limb pains are the most common presenting signs. Radiological evidence is not always present. The prevalence of subclinical rickets is likely to be high, and a screening programme may be needed. Prevention with adequate diet, sun exposure, and vitamin D supplementation is indicated.

The authors were employed by Saudi Aramco during the time the study was conducted and the article written; they acknowledge the use of its facilities for the data and study that resulted in this article. The authors thank Miss Aida Al Noaim, social worker and Mr Munir Hasweh, dietician, for their help.

1 Moncrieff MW, Lunt HR, Arthur LJ. Nutritional rickets at puberty. Arch Dis Child 1973;48:221-4.

2 Kaplan FS, August CS, Fallon MD, et al. Osteopetrorickets. The paradox of plenty. Pathophysiology and treatment. Clin Orthop 1993;(294):64-78.

3 Mazariegos-Ramos E, Guerrero-Romero F, RodriguezMoran M, et al. Consumption of soft drinks with Moran $\mathrm{M}$, et al. Consumption of soft drinks with
phosphoric acid as a risk factor for the development of phosphoric acid as a risk factor for the development of 1995;126:940-2.

4 Meulmeester JF, van den Berg H, Wedel M, et al. Vitamin D status, parathyroid hormone and sunlight in Turkish, Moroccan and Caucasian children in The Netherlands. Eur 7 Clin Nutr 1990;44:461-70.

5 Henderson JB, Dunnigan MG, McIntosh WB, et al. The importance of limited exposure to ultraviolet radiation and dietary factors in the aetiology of Asian rickets: a risk-factor model. $O f M$ 1987;63:413-25.

6 Ekanem EE, Bassey DE, Eyong M. Nutritional rickets in Calabar, Nigeria. Ann Trop Paediatr 1995;15:303-6.

7 el Hag AI, Karrar ZA. Nutritional vitamin D deficiency rickets in Sudanese children. Ann Trop Paediatr 1995;15: 69-76.

8 Lubani MM, al-Shab TS, al-Saleh QA, et al. Vitamin-Ddeficiency rickets in Kuwait: the prevalence of a preventable disease. Ann Trop Paediatr 1989;9:134-9.

9 el-Sonbaty MR, Abdul-Ghaffar NU. Vitamin D deficiency in veiled Kuwaiti women. Eur f Clin Nutr 1996;50:315-18.

10 Sedrani SH, Elidrissy AW, El Arabi KM. Sunlight and vitamin D status in normal Saudi subjects. Am f Clin Nutr

11 Specker BL, Valanis B, Hertzberg V, et al. Sunshine exposure and serum 25-hydroxyvitamin D concentrations in exclusively breast-fed infants. F Pediatr 1985;107:372-6.

12 Williams C, Netzloff M, Folkerts L, et al. Vitamin D metabolism and anticonvulsant therapy: effect of sunshine on incidence of osteomalacia. South Med f 1984;77:8346,842 . 